\title{
Three new species of Maruina Müller (Diptera, Psychodidae) from Brazil
}

\author{
Freddy Bravo
}

Departamento de Ciências Biológicas, Universidade Estadual de Feira de Santana. Avenida Universitária, 44031-460 Feira de Santana, Bahia, Brasil. E-mail: fbravo@uefs.br

\begin{abstract}
Three new species of Maruina Müller, 1895 from Brazil are described, one species from northeastern, Bahia, and two from southeastern, one from Rio de Janeiro and the other from São Paulo. KEY WORDS. South America, Neotropical, Psychodinae.
\end{abstract}

RESUMO. Três espécies novas de Maruina Müller (Diptera, Psychodidae) do Brasil. Neste trabalho são descritas três novas espécies de Maruina Muller, 1895 do Brasil, uma espécie do nordeste, Bahia, e duas do sudeste, uma de Rio de Janeiro e a outra de São Paulo.

PALAVRAS CHAVE. América do Sul, neotropical, Psychodinae.

The genus Maruina Müller, 1895 comprises thirty-four species from the Americas; four from western United States and thirty from the Neotropics (MÜller 1895, KINCAID 1899, JOHANNSEN 1938 Vaillant 1963, 1989, Hogue 1973, 1990, Wagner 1988, 1993, Ibañez-Bernal 1994, Wagner \& Joost 1994, Bravo \& Lago, 2003, Bravo, 2004). Six species of Maruina are known from Brazil: $M$. pilosella Müller, 1895 and M. spinosa Müller, 1895 from Itajaí, Santa Catarina State, southern Brazil (MülLER 1895); three from southeastern Brazil, M. garota Hogue, 1973 and M. namorada Hogue, 1973 from Rio de Janeiro State (Hogue 1973); M. guria Bravo, 2004 from Minas Gerais State (Bravo 2004); and one from Bahia State in northeastern Brazil, M. menina Bravo \& Lago, 2003 (Bravo \& Lago 2003). All the Brazilian species belong to the subgenus Maruina Hogue, 1973 except for M. guria, which belong to the subgenus Alcucina Hogue, 1973. M. pilosella was registered from Tucuman, Argentina (QuATE \& WIRTH 1951) and from São Paulo State, Brazil (BARRETTo 1954). BARRETTO (1954) made a detailed description, including nine figures, of both male and female of M. pilosella, based on specimens from São Paulo. However, some characters observed by BARRETTO (1954) were not figured by MülLER (1895) to the same species. Three new species of Maruina are described here, one of the subgenus Alcucina, from Rio de Janeiro, and two others of the subgenus Maruina, one from São Paulo and one from Bahia, the first are based on specimens identified by BARRETTo (1954) as M. pilosella.

\section{MATERIAL AND METHODS}

All the type material studied are deposited in the entomological collection of Museum of Zoology of the Universidade Estadual de Feira de Santana (CUFS), Feira de Santana, Bahia, Brazil. The specimens from Rio de Janeiro and Bahia were treated with $10 \% \mathrm{KOH}$ and mounted in Canadian balsam. The specimens from São Paulo were previously mounted in Canadian balsam. The terminology used for the description of wings follows Colless \& McAlpine (1991). Morphological terminology follows McAlpine (1981).

\section{RESULTS AND DISCUSSION}

\section{Maruina (Alcucina) duckhousei sp. nov. Figs $1-7$}

Type material. Holotype male and one paratype male: BrAZIL, Rio de Janeiro State: Represa Rio Grande, IX.1969, M. Alvarenga leg. (CUFS).

Etymology. Named in honor of Dr. Derek A. Duckhouse in recognition of his contribution to psychodid systematics.

Description. Male. Holotype without cerci and flagellomeres. Length from thorax to the posterior end of abdomen, $2.12 \mathrm{~mm}$.

Head. Subcircular in frontal view; eye bridge approximate, interocular space equal to $1 / 4$ facet diameter (Fig. 1). Antenna incomplete in paratype; scape cylindrical; pedicel spherical, smaller than scape (Fig. 2); flagellomeres barrel-shaped (Fig. 3 ); ascoids lost. Palpi with four articles; relative length of palpomeres 1.0:1.7:2.1:3.7 (Fig. 4).

Thorax. Wing (Fig. 5) lanceolate; wing length $1.74 \mathrm{~mm}$; maximum width $0.54 \mathrm{~mm}$; with $\mathrm{R}_{5}$ ending at tip. Sc short, not reaching $C ; \mathrm{R}_{3}$ jointed to $\mathrm{R}_{2+3}$.

Abdomen. Sternites 5-8 without internal sclerotized bands; tergite 7 with a pair of long-bristled tufts.

Male terminalia (Fig. 7). Gonocoxites and gonostyles with pilosity; cerci of paratype with pilosity; gonocoxites with approximately 29 bristles on the dorsal surface; sternite 10 with apical micropilosity. Tergite 9 plate-like, rectangular. Sternite 9 

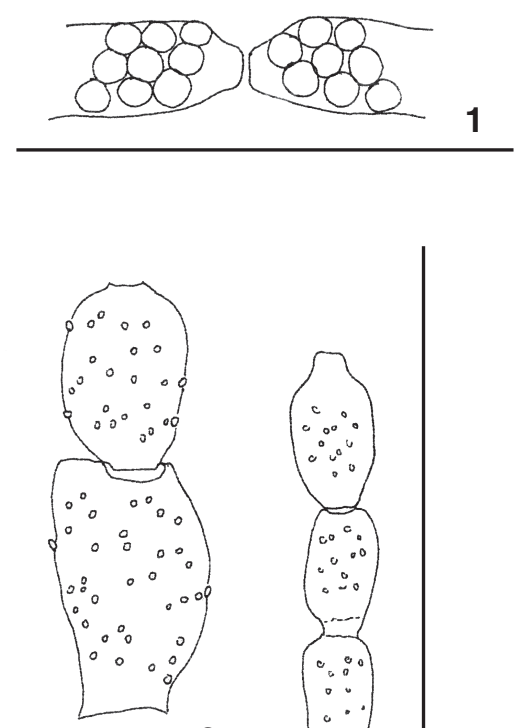

2

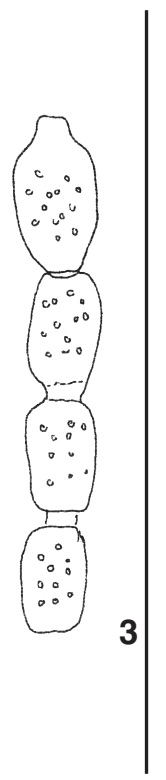

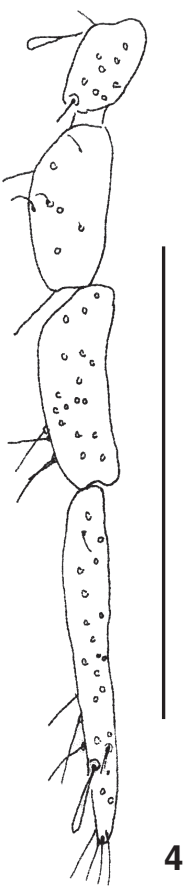

4
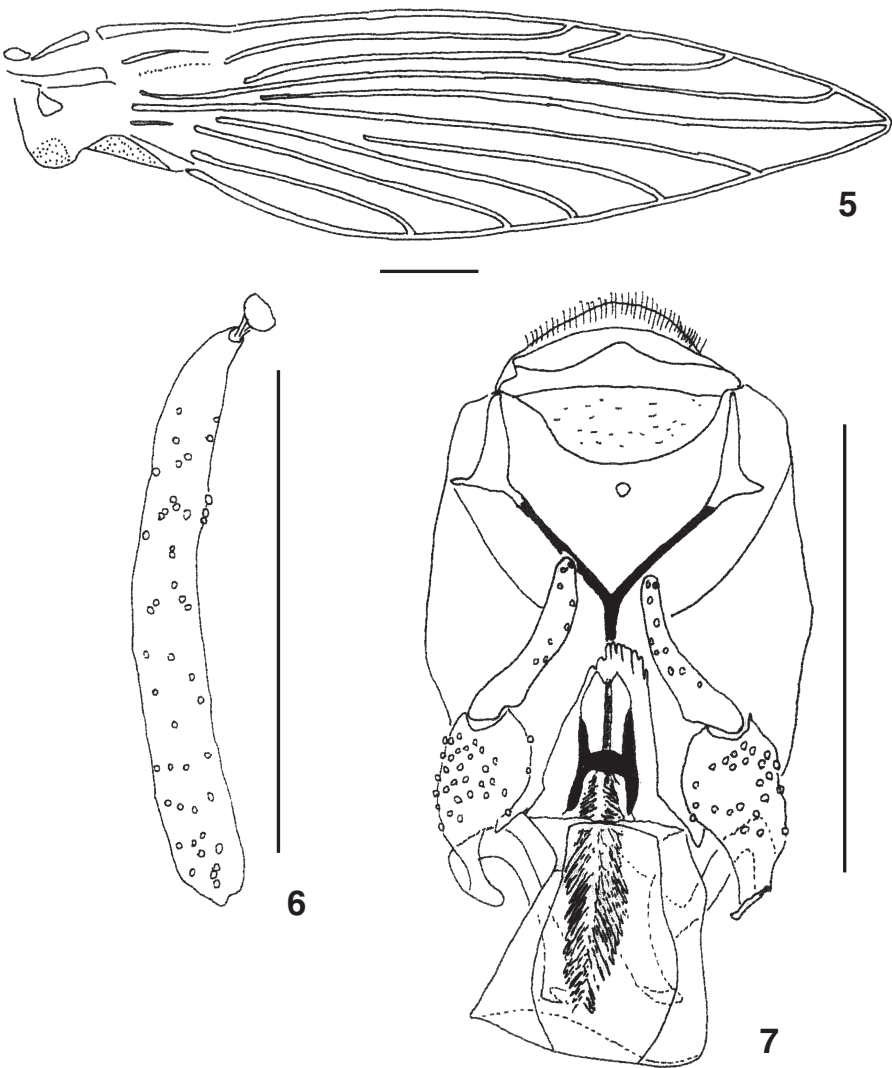

Figures 1-7. Maruina duckhousei sp. nov. Male. 1. Eye bridge (holotype). 2. Base of antenna (scape, pedicel) (holotype). 3. Flagellomeres I-IV (paratype). 4. Palpus (holotype). 5. Wing (holotype). 6. Cercus (paratype). 7. Male terminalia, dorsal view (holotype). Scale lines: $0.2 \mathrm{~mm}$.

lacking. Gonostyle digitiform. Aedeagus symmetrical; aedeagal spines monomorphic, short and thin. Aedeagal sheath wide at distal end, with median sclerotized area. Aedeagal apodema slightly longer than gonocoxite. Gonocoxal apodema smaller than aedeagal apodema. Cerci digitiform with a single apical tenaculum in the paratype (Fig. 6).

Comments. M. duckhousei sp. nov. belongs to the subgenus Alcucina Hogue, 1973. This new species presents the following characters that are unique to Alcucina (Hogue 1973, Bravo 2004): contiguous ocular bridge, $\mathrm{R}_{2}$ united to $\mathrm{R}_{3}$, sternite 9 absent, and aedeagal spines monomorphic.

From the 11 neotropical previously known species of Maruina (Alcucina), only one is known from Brazil (Bravo 2004). M. duckhousei sp. nov. can be distinguished from other species of the subgenus by the space separating the eye bridge. In the new species this space is $1 / 4$ of the diameter of the ocular facet, while in most species of Maruina (Alcucina) the space between the eye bridge is equal to 1 to 4 facet diameters (except in the brazilian species, M. guria Bravo, 2004, in which it is contiguous).

Maruina duckhousei sp. nov. differs from M. guria for the presence of monomorphic aedeagal spines.
Among the species of Alcucina subgenus, only M. muchacha Hogue, 1973 and M. duckhousei sp. nov. have similar male terminalia. However, M. muchacha has a wide aedeagal apodem while in the new species it is narrow. An additional difference between the two species is the location of the sclerotized area of the aedeagal sheet: in M. muchacha it is apical, while in $M$. duckhousei sp. nov. it is medial.

\section{Maruina (Maruina) barrettoi sp. nov. Figs 8-16}

Type material. Holotype male, thirteen paratypes male and seven paratypes female: BraziL, São Paulo State: Rancharia, Usina Caiuá, M. Barretto leg. (CUFS).

Etymology. Named in honor of Prof. Mauro Barretto, an important Brazilian psychodids researcher.

Description. Male. Length from thorax to the posterior end of the abdomen, $1.66 \mathrm{~mm}$.

Head. Subcircular in frontal view; eye bridge joined by a sclerotized band; interocular space equal to nine facet diameters (Fig. 8). Antenna with 14 flagellomeres; scape cylindrical; 


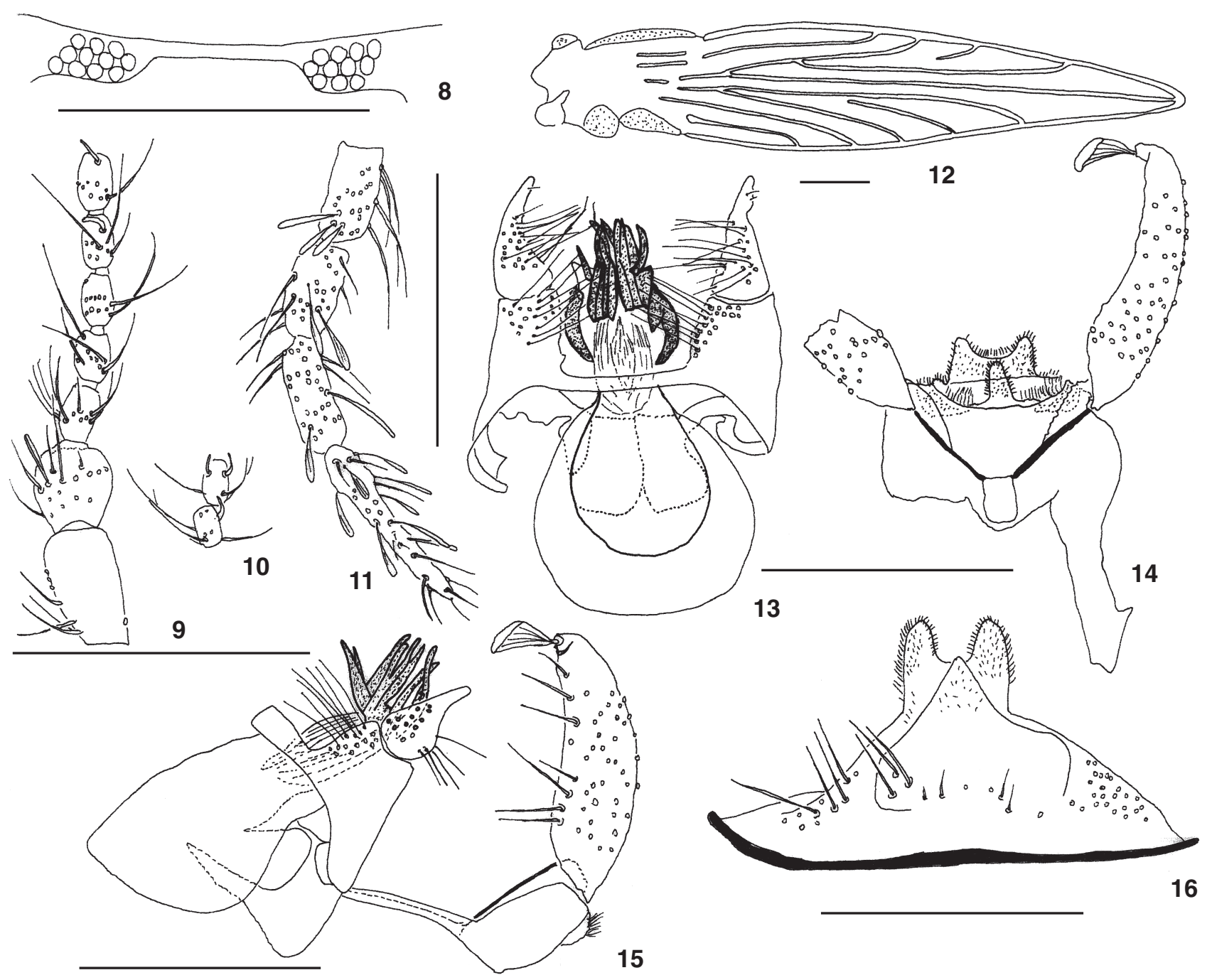

Figures 8-16. Maruina barrettoi sp. nov. Figures 1-15, holotype male. 8. Eye bridge. 9. Scape, pedicel and five flagellomeres. 10. Flagellomeres XIII-XIV. 11. Palpus. 12 Wing. 13. Male terminalia, dorsal view. 14. Male terminalia, cerci, tergite IX and sternite X. 15. Male terminalia, lateral. 16. Allotype, sternite VIII. Scale lines: $0.2 \mathrm{~mm}$.

pedicel spherical, smaller than scape (Fig. 9); flagellomeres barrel-shaped; a pair of short, single filamented ascoids are present after flagellomere 4 (Figs 9, 10). Palpi with four articles; relative lengths of palpomeres 1.0:0.9:1.1:2.0 (Fig. 11).

Thorax. Wing (Fig. 12) lanceolate; wing length $1.71 \mathrm{~mm}$; maximum width $0.38 \mathrm{~mm}$, with $\mathrm{R}_{5}$ ending at tip; $\mathrm{R}_{2}$ incomplete, not united to $\mathrm{R}_{3} ; \mathrm{M}_{2}$ not united to $\mathrm{M}_{1}$.

Male terminalia. Cerci, gonocoxites, and gonostyles with pilosity (Figs 13, 14); gonocoxites with approximately 20 bristles on the dorsal surface; sternite 10 with apical micropilosity (Fig. 14). Tergite 9 plate-like, rectangular (Fig. 14). Sternite 9 present, narrow (Fig. 13). Cerci digitiform, with a single apical tenaculum (Figs 14, 15). Gonostyle triangular, with base wider than apex (Fig. 13). Aedeagus symmetrical; aedeagal spines dimorphic, apical spines thick, basal spines small and thin (Figs 13, 14). Aedeagal sheath wide, with lateral sclerotized area. Aedeagal apodema wide, circular in dorsal view (Fig. 14). Gonocoxal apodema smaller than aedeagal apodema (Fig. 15).

Female. Similar to male except for the following: length of body $1.96 \mathrm{~mm}$. Relative length of palpomeres: 1.0:1.0:1.1:2.0. Wing length $2.04 \mathrm{~mm}$; maximum width $0.42 \mathrm{~mm}$. Subgenital plate conical with two lobes short (Fig. 16).

Comments. M. barretoi sp. nov. belongs to the subgenus Maruina Hogue, 1973. This new species presents the following characters that are unique to the subgenus Maruina (Hogue 1973, BRAVO 2004): presence of dimorphic edeagal spines, with the 


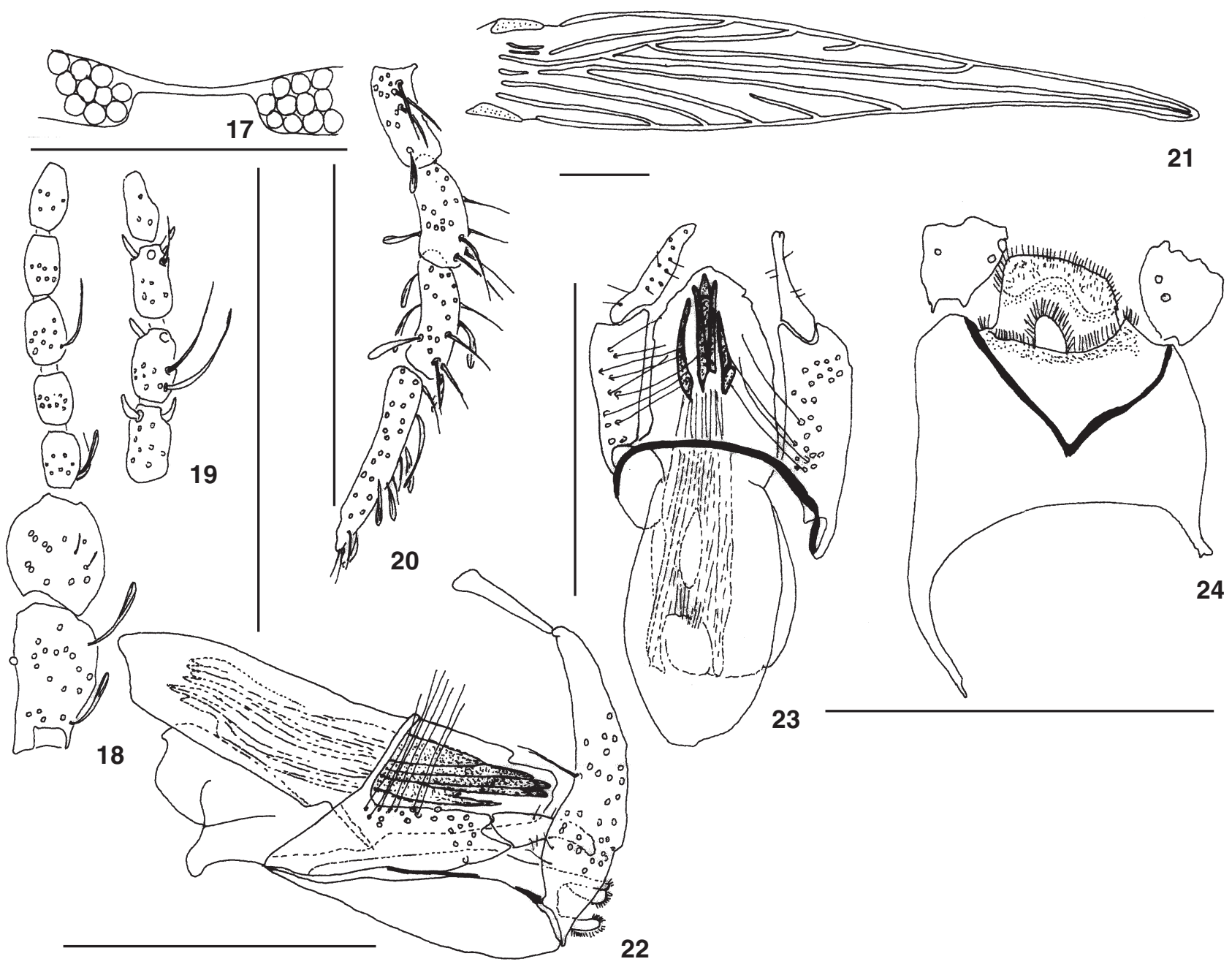

Figures 17-24. Maruina jezeki sp. nov. Holotype male. 17. eye bridge. 18. Scape, pedicel and five flagellomeres. 19. Flagellomeres XIXIV. 20. Palpus. 21. Wing. 22. Male terminalia, lateral. 23. Male terminalia, dorsal. 24. Male terminalia, tergite IX and sternite X. Scale lines: $0.2 \mathrm{~mm}$.

posterior ones being much heavier and shorter than the anterior, ninth male sternite well developed, with a well sclerotized subgenital plate, eye bridge separated by 7 to 10 facet diameters, and $\mathrm{R}_{3}$ not united to $\mathrm{R}_{2}$. There are 23 known species of Maruina (Maruina), five of them from Brazil (Bravo 2004).

The specimens studied here were identified by BARRETTO (1954) as Maruina pilosella. There is no evidence of long aedeagal spines on the aedeagal sheet, similar to those observed in all males of this species from São Paulo, in the figures of M. pilosella made by MüLLER (1895: figs 19, 20). Another difference between the new species described here and the drawings of MüLLER (1895) is the relative size of the gonostylus, smaller than the gonocoxite in M. pilosella and larger in M. barrettoi sp. nov.

Only two other species are known to have aedeagal spines projected besides the aedeagal sheet: M. boulderina Vaillant, 1963 and M. lanceolata (KINCAID 1899), both from northern of Mexico. M. boulderina has an incomplete sternite 9, while in $M$. duckhousei sp. nov. it is complete. In M. lanceolata the gonostylus is smaller than the gonocoxite, while in M. duckhousei sp. nov. it is larger.

\section{Maruina (Maruina) jezeki sp. nov.}

Figs 17-24

Type material. Holotype male and two paratype males: Brazil, Bahia State: Cachoeira, Fazenda Villa Rial, 24.V.2004, F. Bravo leg. (CUFS).

Etymology. Named in honor of Dr. Jan Jezek in recognition of his contribution to psychodid systematics. 
Description. Male. Length from thorax to the posterior end of abdomen, $1.47 \mathrm{~mm}$.

Head. Subcircular in frontal view; eye bridge joined by a sclerotized band; interocular space equal to seven facet diameters (Fig. 17). Incomplete antenna in the specimens studied; scape cylindrical; pedicel spherical, smaller than scape (Fig. 18); flagellomeres barrel-shaped; a pair of short, single-filamented ascoids (Fig. 19). Palpi with four articles; relative length of palpomeres 1.0:1.1:1.3:1.8 (Fig. 20).

Thorax. Wing lanceolate (Fig. 21); wing length $1.63 \mathrm{~mm}$; maximum width $0.27 \mathrm{~mm}$; wing with very narrow apex; $\mathrm{R}_{5}$ ending at tip; $\mathrm{R}_{2}$ incomplete, not united to $\mathrm{R}_{3} ; \mathrm{M}_{2}$ not united to $\mathrm{M}_{1}$.

Male terminalia. Cerci, gonocoxites, and gonostyles with pilosity (Figs 22, 23); gonocoxites with approximately 25 bristles on the dorsal surface; sternite 10 with apical micropilosity (Fig. 24). Tergite 9 plate-like, rectangular (Fig. 24). Sternite 9 present, narrow (Fig. 23). Cerci digitiform, with a single apical tenaculum (Fig. 22). Gonostyle digitiform, smaller than gonocoxite (Fig. 23). Aedeagus symmetrical; aedeagal spines dimorphic, apical spines thick, while basal spines small and thin (Figs 22, 23). Aedeagal sheath wide, without median sclerotinized area. Aedeagal apodema as long as gonocoxite (Figs 22, 23). Gonocoxal apodema smaller than aedeagal apodema (Fig. 22).

Comments. In agreement with the characteristics mentioned above for M. barretoi sp. nov., M. jezeki sp. nov. belongs to the subgenus Maruina.

Seven species of the subgenus Maruina have an incomplete sternite 9, while in M. barrettoi sp. nov. and in other 15 species it is complete (according to Bravo 2004: table 1). MülLER (1895) did not mention this structure for M. spinosa Müller, 1895, from southern Brazil.

Maruina jezeki sp. nov. has a complete sternite 9. Wing drawings are available for only 7 species (of the 16 species of M. (Maruina) with a complete sternite 9): M. barrettoi sp. nov., M. hoguei Wagner, 1993, M. lanceolata (Kinkaid, 1899), M. menina Bravo \& Lago, M. mollesi Vaillant, 1989, M. pilosella Müller, 1895, and M. tobagensis Wagner, 1993 (Bravo 2004). None of these seven species has the wing shape as in M. jezeki sp. nov., with a very narrow apex in relation to the middle area of the wing.

The remaining nine species of the subgenus Maruina having a complete sternite differ from $M$. jezeki sp. nov. by: $M$. dama Hogue, 1973 and M. garota Hogue, 1973 have monomorphic aedeagal spines, while in $M$. jezeki sp. nov. it is dimorphic; M. penaki Vaillant, 1963 has narrower aedeagal spines than M. jezeki sp. nov.; the aedeagal spines of M. nina Hogue, 1973 and M. bellaca Hogue, 1973 reach the apex of the edeagal sheet, while in $M$. jezeki sp. nov. they reach only the middle portion of the edeagal sheet; M. vidamia Hogue, 1973 has a bifurcated gonostylus, while in M. jezeki sp. nov. it is simple; the apex of the gonostylus of M. pebeta Ibañez-Bernal, 1994 is acute, while in M. jezeki sp. nov. it is rounded; the gonostyle of the M. jezeki sp. nov. is half the length of the gonocoxite, while in M. chamaquita Hogue, 1973, and M. namorada Hogue, 1973, it is larger than the gonocoxite.

Maruina spinosa was probably described by using an exemplar female. The type material has been lost. The drawing of the head (MülLER 1895: fig. 16) is typical of Maruina (Maruina). The base of the abdomen seems to be that of a female (MüLLER 1895: fig. 17). The apex of the wing is very rounded (Müller 1895: fig. 14) and is different from any other known species of the subgenus Maruina.

\section{ACKNOWLEDGMENTS}

The author has financial support from CNPq (470754/ 2003-6) and FAPESB (PPP) and has a research grant of CNPq (307357/2003-1).

\section{REFERENCES}

Barketto, M.P. 1954. Sobre o gênero Maruina F. Müller, 1895 (Diptera, Psychodidae). Revista Brasileira de Zoologia, São Paulo, 2: 61-69

Bravo, F. 2004. Maruina guria (Diptera, Psychodidae), a new psychodid species from Brazil. Zootaxa, New Zealand, 614: 1-7.

Bravo, F. \& A.P. Lago. 2003. Maruina menina, uma nova espécie de Psychodidae (Diptera) do Brasil. Iheringia, Série Zoologia, Porto Alegre, 93 (4): 395-398,

Colless, D.H. \& D.K. McAlpine. 1991. Diptera, p. 717-786. In: CSIRO (Ed). The insects of Australia. Victoria, Melbourne University, 1137p.

Hogue, C.L. 1973. A taxonomic review of the genus Maruina (Diptera, Psychodidae). Science Bulletin Natural History Museum, Los Angeles, 17: 1-69.

Hogue, C.L. 1990. A remarkable new species of Maruina (Diptera, Psychodidae) from Colombia. Aquatic Insects, Lisse, 12: 185-191.

IBÁNEZ-BERnaL, S. 1994. Maruina (Maruina) pebeta: a new species of torrenticolous Psychodidae (Diptera) of Cordoba Province, Argentina. Revista Brasileira de Entomologia, São Paulo, 38 (1): 57-62.

Johannsen, O.A. 1938. New species of Nemocera from Puerto Rico. The Journal of Agriculture of the University of Puerto Rico, San Juan, 22: 219-225.

Kincaid, T. 1899. The Psychodidae of the Pacific Coast, Entomological News, Philadelphia, 10: 30-37.

McAlpine, J.F. 1981. Morphology and terminology: adults, p. 963. In: J.F. McAlpine; B.V. Peterson; G.E. Shewell; H.J.Teskey; J.R. Vockeroth \& D.M. Wood (Eds). Manual of Neartic Diptera. Ottawa, Research Branch, Agriculture Canada, Monograph 27, vol. 1, 674p.

MülLER, F. 1895. Contributions towards the history of a new form of larvae of Psychodidae (Diptera) from Brazil. Transactions of the Royal Entomological Society of London 1895: 479-482. 
Quate, L.W. \& W.W. WirTh, 1951. A taxonomic revision of the genus Maruina (Diptera: Psychodidae). The Wasmann Journal of Biology, San Francisco, 9: 151-166.

Vaillant, F. 1963. Les Maruina d'Amérique du Nord (Diptera, Psychodidae). Bulletin de la Société Entomologique de France, Paris, 68: 71-91.

Vaillant, F. 1989. Les Diptères Psychodidae Psychodinae dont les larves sont pourvues de ventouses ventrales. Annales de la Société Entomologique de France (N. S.), Paris, 25: 1723.

Received in 17.XI.2004; accepted in 03.VIII.2005.
WAGNER, R. 1988. The first representative of the moth-fly genus Maruina Müller, 1895 from Peru (Diptera: Psychodidae). Studies on Neotropical Fauna and Environment, Lisse, 23: 55-57.

Wagner, R. 1993. On a collection of Psychodidae (Diptera) by Dr. L. Botosaneanu from some Caribbean islands. Aquatic Insects, Lisse, 15: 109-127.

Wagner, R. \& W. Joost. 1994. On a small collection of Psychodidae (Diptera) from Colombia. Studies on Neotropical Fauna and Environment, Lisse, 29: 75-86. 